\title{
Clinicopathological study of recipients' corneal tissue excised during penetrating keratoplasty. Best out of waste!
}

\author{
Anupama P. Gupta ${ }^{1, *}$, Ganesh H. Hake ${ }^{2}$, Dinkar T. Kumbhalkar ${ }^{3}$, A. H. Madan ${ }^{4}$ \\ ${ }^{\mathbf{1}}$ Associate Professor, Dept. of Pathology, Government Medical College Nagpur, Maharashtra, ${ }^{2}$ Blood Transfusion Officer, Sub \\ District Hospital Baramati, Pune, Maharashtra, ${ }^{3}$ Professor, ${ }^{4}$ Professor and Head, ${ }^{3}$ Dept. of Pathology, ${ }^{4}$ Dept. of Ophthalmology, \\ Government Medical College Nagpur, Maharashtra, India
}

\section{*Corresponding Author: Anupama P. Gupta}

Email: pama_gpta@rediffmail.com

\begin{abstract}
Introduction: Corneal buttons removed during penetrating keratoplasties (PK) from recipients' which were routinely discarded were studied with aim to analyze the common indications of PK and changing pattern of corneal diseases in developing countries like India.

Materials and Methods: This is an observational case series carried out in tertiary care hospital of central India from October 2012 to October 2014. Histopathology of 156 corneal tissues was done of which 75 were recipients' corneal tissues removed during PK and 81 were residual adjacent donors' corneal tissues left out after corneal button was removed for transplant.

Results: The most common indication of PK in our study was corneal ulcer $(n=37,49.33 \%)$, followed by infectious keratitis $(\mathrm{n}=22,29.33 \%)$ which included ulcers in various stages of healing and complications associated with ulcer like adherent leucoma. Amongst infectious keratitis, 17 were $(77.27 \%)$ of bacterial keratitis and 5 (22.73\%) of fungal keratitis. Followed by bullous keratopathy $8(10.66 \%), 3(4 \%)$ of graft rejection and one each $(1.33 \%)$ of Fuchs' dystrophy and chronic actinic keratopathy.

Of 81 donor's corneal tissues, 75 were the residual corneal tissues from corneo-conjunctival junction which were transplanted within stipulated time. Only one case showed changes of chronic actinic keratopathy, rest showed normal histology. 6 corneas which were not transplanted within stipulated time showed epithelial denudation and stromal degeneration with loss of keratocytes.

Conclusion: Histopathology gives additional insight to clinical diagnosis. Specific diagnosis can be commented in corneal opacities and infectious keratitis.
\end{abstract}

Keywords: Penetrating Keratoplasty, PK, Histopathology, Corneal buttons, Recipient.

\section{Introduction}

Corneal blindness is one of the most challenging public health problems all over the world. Corneal diseases are a significant cause of visual impairment and blindness in the developing world especially India where it is one of the leading causes of visual disability. ${ }^{1-3}$

The epidemiology of corneal blindness encompasses a wide variety of infectious and inflammatory eye diseases that cause corneal scarring, which ultimately leads to functional blindness. Prevalence of corneal disease varies from country to country and even from one population to another. Cataract is responsible for nearly 20 million of the 45 million blind people in the world, followed by trachoma which blinds 4.9 million individuals, mainly as a result of corneal scarring and vascularization. Ocular trauma and corneal ulceration are significant causes of corneal blindness that are often under reported but may be responsible for 1.5-2.0 million new cases of monocular blindness every year. ${ }^{1-3}$

Since the first full-thickness corneal transplantation reported by Zirm, ${ }^{4}$ penetrating keratoplasty (PK) has become one of the most popular and successful organ transplantation techniques used worldwide in treatment of various corneal diseases. ${ }^{5}$ There are many recent reports about the indications for PK in the developed world, ${ }^{6-11}$ but to our knowledge, recent information regarding this aspect on a large series of patients is not available from the developing world.

The indications for PK vary with economic development, geographic region and social conditions. With the spread of phacoemulsification and intraocular lens (IOL) implantation, corneal edema following cataract surgery increased abruptly, and has been the leading indication in the developed countries (e.g, US and Europe) since the 1980s. ${ }^{12,13}$ At the same time, the leading indications for PK in developing countries (e.g, China and India) have remained infectious keratitis, corneal scarring. ${ }^{14-16}$

Indications for corneal transplantation have changed over time, especially during the last decade. ${ }^{13}$ Since there is changing trend in indications of penetrating keratoplasty, histopathology along with clinical correlation will be helpful in establishing and categorizing indications of penetrating keratoplasty. Categorization of various infective causes and identification of unusual infectious agent will have clinical implication and help clinicians in post-operative management of patients.

The purpose of the present study was to evaluate the indications for $\mathrm{PK}$ at our institution which is a major referral centre in the central India for the treatment of corneal diseases and its comparison with 
the indications for PK reported from the other developing and developed countries.

\section{Materials and Methods}

This is an observational prospective study carried out at tertiary care centre in central India. Present study was carried out with the aims: 1. To study histopathology of corneal buttons removed during PK and correlate with clinical diagnosis. 2. To study the leading indications of penetrating keratoplasty in tertiary care hospital. 3. To emphasize the importance of histopathological study of recipients' corneal buttons removed during keratoplasty.

Inclusion Criteria: All recipients' corneal buttons removed during penetrating keratoplasty (PK) irrespective of age, sex and clinical diagnosis were included in study with no exclusion criteria. In addition residual donors' tissue left out after corneal transplant were also included.

After ethical approval and informed consent total 156 corneal tissues, of which 75 were recipients' corneal tissues removed during penetrating keratoplasty (PK) and 81 residual donors' corneal tissues stored in Mc Carey-Kaufman (MK) medium suitable for corneal transplant were studied. Of 81 donors' cornea, 75 were the residual corneal tissues from the corneal buttons which were transplanted to recipients within stipulated time (5 days) by ophthalmologist and rest 6 were corneal tissues which were not transplanted within stipulated time and provided to us by Ophthalmologist for histopathological evaluation.

Patients with suspected corneal blindness were examined with detailed history with emphasis on occupation, any trauma, any systemic illnesses like diabetes, hypertension. Each patient underwent detailed ophthalmic examination including slit-lamp examination by Ophthalmologist. The corneal tissues after PK were bisected; one section was sent for microbiological culture and another half for histopathological examination which was fixed in $10 \%$ formalin, paraffin embedded and sections studied by routine haematoxylin and eosin (H and E) staining. Special stains like Per Iodic Acid Schiff stain (PAS), Congo red were done as and when needed. Gram staining and $\mathrm{KOH}$ mounting along with culture in Sabouraud dextrose agar, blood agar, and thioglycolate broth was done for microbiological study.

We classified corneal lesions according to Parson and Myronn Yanoff as follows. ${ }^{17,18}$

Classification: 1 Infectious Keratitis -a) Acute Keratitis, Bacterial, Fungal etc.; b) Corneal ulcer/Opacities (Healing, Healed, With complicationAdherent leukoma), 2 Keratopathy, 3 Dystrophy, 4 Graft rejection

Statistical Evaluation: Categorical variables, sex, indications, socioeconomic status were expressed in actual numbers \& percentages and age as mean +/standard deviation. Various indications of PK were compared across different age, sex by performing 'Pearson's chi-square test. For small numbers Fishers' exact test was applied. Correlation between clinical and histopathological diagnosis was assessed by calculating sensitivity, specificity, concordance rate for different indications of PK. P value $<0.05$ was considered as statistically significant. Statistical software STATA version 13.1 was used for data analysis.

\section{Results}

Total 156 corneal buttons were studied. Out of which 75 were recipients' corneal tissues removed during PK and 81 were donors' corneal tissues. The mean age of the recipients' was $50.43+/-14.33$ years (range 11-76 years) with M: F-59:41. 70.66\% of the recipients were below poverty line (BPL), with main occupation being agriculture, $n=52(69.33 \%)$. The most common histological indication of PK in our study was corneal ulcer $(n=37,49.33 \%)$, followed by infectious keratitis $(\mathrm{n}=22,29.33 \%)$. Corneal ulcer $(\mathrm{n}=37,49.33 \%)$ included ulcers in various stages of healing (healing08, healed scar- 19) and complications associated with ulcer like adherent leucoma $(\mathrm{n}=10)$. [Fig 1A-D, 2D] Impacted foreign body was detected in one case. Of 22 cases of infectious keratitis, $17(77.27 \%)$ were of bacterial keratitis and $5(22.73 \%)$ of fungal keratitis (Aspergillus $(\mathrm{n}=3)$ and Fusarium $(\mathrm{n}=2)$ on culture). [Fig 2 A- C]We found $8(10.66 \%)$ cases of bullous keratopathy, 1 (1.33\%) of Fuchs' dystrophy, 1 (1.33\%) of chronic actinic keratopathy and graft rejection $(n=3$, $4 \%$ ), which included rejection due to various causes like stromal vascularisation, acute keratitis and bullous keratopathy (1 case of each). [Fig 3 A-D] In present study, in $13.66 \%$ of cases, clinical and histopathological diagnosis did not correlate. And this association was found often with corneal ulcer, infectious keratitis, Fuchs' dystrophy and chronic actinic keratopathy. Thus sensitivity of clinical diagnosis for infectious keratitis, corneal ulcer, was $77.27 \%, 86.49 \%$ respectively and specificity was $88.68 \%, 76.22 \%$ respectively, and $\mathrm{P}$ value $<0.001$. Concordance rate of clinical diagnosis and histopathological diagnosis for infectious keratitis and corneal ulcer was $85.33 \%, 81.30 \%$ respectively. Concordance was $100 \%$ in bullous keratopathy and graft rejection. Specific cause of graft rejection could be given on histopathology. Cases of Fuchs' dystrophy and chronic actinic keratopathy were not clinically suspected and reported on histopathology.

Of 81 donors cornea 75 were the residual corneal tissues from corneo-conjunctival junction which were transplanted within stipulated time. 74 of them showed a part of cornea with unremarkable histology. Only one case aged 82 years showed changes of chronic actinic keratopathy. 6 corneas which were not transplanted within stipulated time showed changes of degeneration in the form of epithelial denudation and stromal degeneration with loss of keratocytes. 


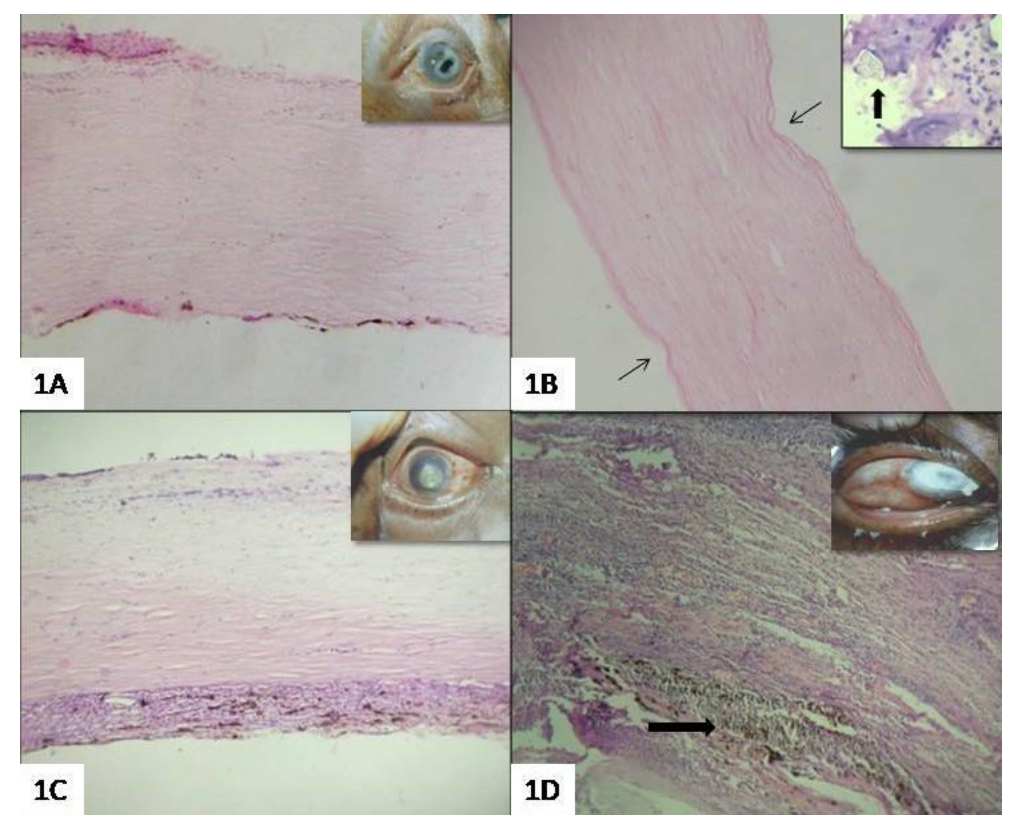

Fig. 1 (A-D): (H \& E 40X) Clinical and histopathology images - (A: Healed ulcer showing ulceration of the corneal epithelium; (B: Healed scar with haphazard stromal fibers and kinking of fibers (arrows), inset showing impacted foreign body (block arrow); (C: Adherent leucoma showing iris tissue adherent to posterior surface of cornea; (D: Perforated corneal ulcer with iris incarceration into stroma

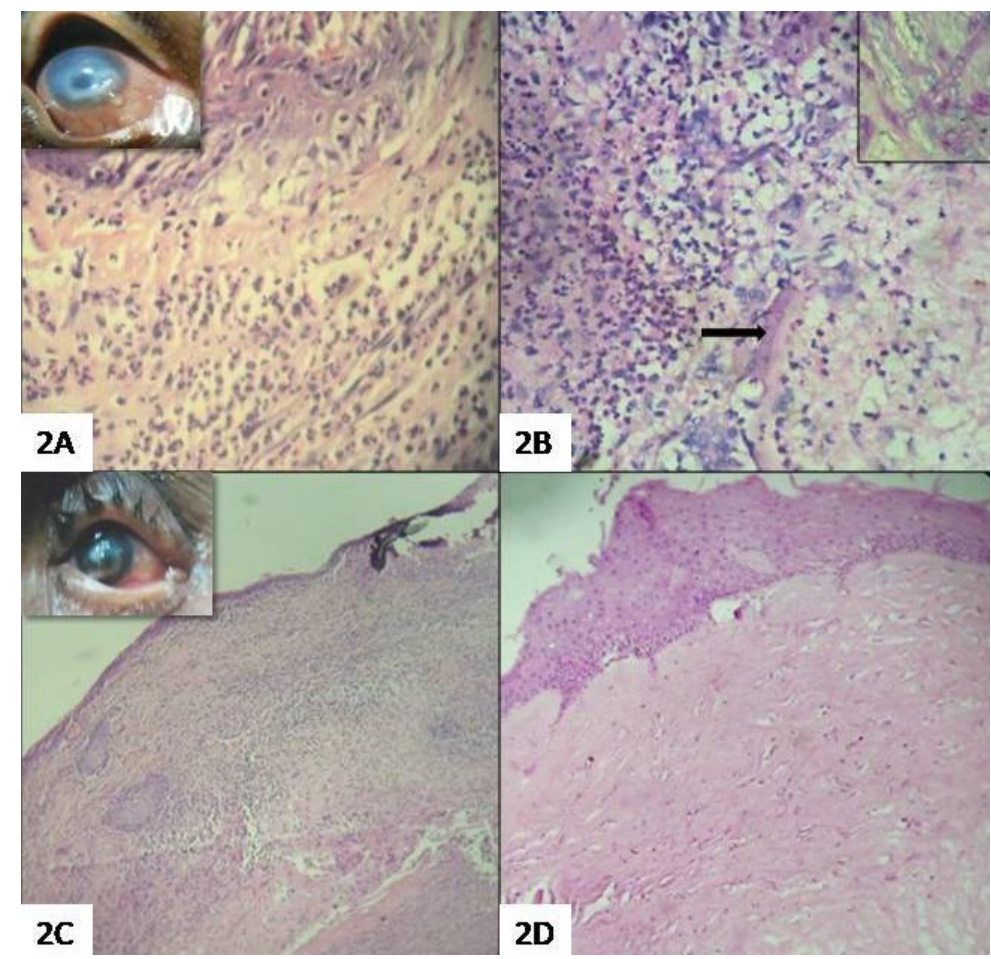

Fig. 2 (A-D): (H \& E 40X) Clinical \& histopathology images- (A: Showing Acute infectious keratitis with acute inflammatory infiltrate in the stroma; (B: Fungal keratitis showing hyphae, inset showing PAS positive fungal hyphae; (C: Showing corneal abscess with exuberant acute inflammatory exudate and necrosis, inset showing clinical image of hypopion; (D: Corneal ulcer showing conjuctivization in initial stage of healing 


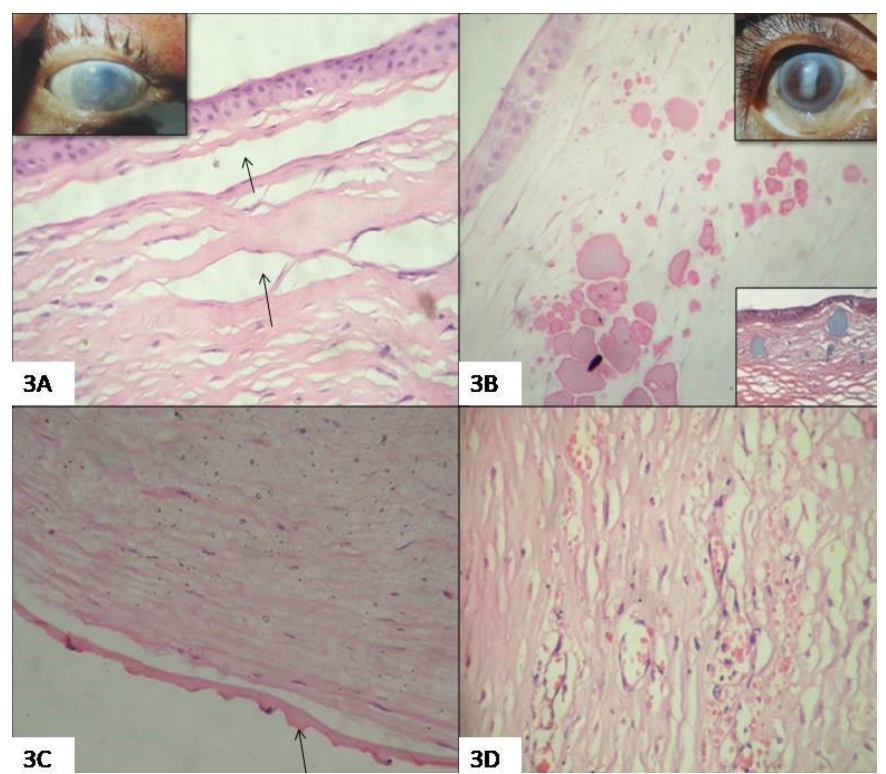

Fig. 3 (A-D): (H \& E 40X) Clinical \& histopathology images (A: Bullous keratopathy showing subepithelial bullae and separation of sromal fibers due to edema, inset showing clinical picture; (B: Corneal opacity showing subepithelial collection of eosinophilic homogeneous material with calcification in chronic actinic keratopathy. Upper inset showing corneal opacity and negative Congo red stain in lower inset; (C: Guttae (arrow) at Descemet membrane and stromal edema suggesting Fuchs' dystrophy; (D: Image showing graft rejection due to stromal vascularization

\section{Discussion}

Since the first full-thickness corneal transplantation reported by Zirm, ${ }^{4}$ penetrating keratoplasty (PK) has become the most popular and successful organ transplantation techniques used worldwide which can visually rehabilitate. patients with corneal blindness. The prognosis of the outcome, however, is dependent on the pathology responsible for causing corneal blindness or visual impairment, ${ }^{6}$ which vary with geographic regions along with economic development and social conditions. The purpose of our study was to study the histomorphology in recipients' corneal buttons removed during $\mathrm{PK}$ and document the indications for PK in our institute which is a major referral centre for the treatment of corneal diseases. In addition, residual corneal tissue from donors' was also studied.

Of 156 corneal 75 were recipients' cornea and 81 were donors cornea. The mean age of the patients was $50.43+/-14.33$ years (Range 11-76 years) with male preponderance $(59 \%)$. In our institute, PKs are done free of cost under National Programme for Control of Blindness (NPCB) thus $70.66 \%$ of our patients were below poverty line (BPL). In Indian study by Dandona et $\mathrm{al}^{5} 66.7 \%$ patients were of high socioeconomic status as compared to $33.3 \%$ patients of low socioeconomic status. They also implied that patients with lower socioeconomic status may be more prone to corneal scarring and active infectious keratitis and in the patients of higher socioeconomic status as PK was done for pseudophakic or aphakic bullous keratopathy, it may be because patients with higher socioeconomic status are more likely to get cataract surgery done than those with lower socioeconomic status.

Most common occupation in our study was agriculture, $\mathrm{n}=52(69.33 \%)$ accounting for corneal trauma with thorn/husk in farm workers followed by ocular infection. Similar study by Wang JY et al from Shandong, ${ }^{13}$ a large agriculture province, reported large proportion of farm workers with poor safety awareness, low medical services and ineffective treatment being reason for the higher prevalence of Infectious keratitis in these patients. Usha Gopinathan et $\mathrm{al}^{19}$ also commented that agriculture based activities were at 1.33 times greater risk of acquiring microbial keratitis which increases with ocular trauma.

The most common indication of PK in our study was corneal ulcer $(n=37,49.33 \%)$, followed by infectious keratitis $(n=22,29.33 \%)$ thus ulcers in various stages of healing and acute infectious keratitis together were the most common indication of PK $(n=59,78.66 \%)$. Of 22 cases of infectious keratitis, 17 $(77.27 \%)$ were of bacterial keratitis and $5(22.73 \%)$ of fungal keratitis. Bacterial keratitis corneas showed no growth on culture as all of them were given topical and systemic antibiotics whereas 5 showed fungal organisms, consistent with Aspergillus $(\mathrm{n}=3)$ and Fusarium ( $\mathrm{n}=2)$ on culture.

Wang JY et $\mathrm{al}^{13}$ from China also reported infectious keratitis (325 cases, 37.1\%) as the leading indication for PK, followed by HSK (167 cases, $19.1 \%$ ), keratoconus (98 cases, 11.2\%), bullous keratopathy (74 cases, 8.5\%), regrafting (59 cases, $6.7 \%$ ), corneal scarring (42 cases, $4.8 \%$ ), similar to our study where infectious keratitis was the second most 
common leading indication. We did not find any case of herpes simplex keratitis (HSV) keratitis, due to improvement in the clinical recognition and medical treatment of herpes simplex keratitis which correlated well with the study by Sharif et al. ${ }^{20}$ In a study by Sony $\mathrm{P}$ et al, ${ }^{14}$ corneal infections either active $(28.38 \%)$ or healed $(38.01 \%)$ were the most common indication for keratoplasty in northern India. Chen WL et al ${ }^{16}$ reported the leading indications for $\mathrm{PK}$ to be corneal scars $(27.9 \%)$, acute necrotizing and ulcerative keratitis (17.9\%). Rajpal Singh Puniya reported ${ }^{21}$ Aspergillus flavus $(59.09 \%)$ being commonest followed by Fusarium. Sirikul et al ${ }^{22}$ reported bacterial keratitis (76 eyes, 60\%), followed by fungal (48 eyes, 38\%) and Acanthamoeba keratitis (3 eyes, 2\%) where Pseudomonas spp. was the commonest bacteria and Fusarium being the commonest fungus.

Most common indication of PK in our study was corneal ulcer $(n=37,49.33 \%)$. It included ulcers in various stages of healing (healing- 08, healed scar-19) and complications associated with ulcer like adherent leucoma $(n=10)$. In one case of healed corneal ulcer impacted foreign body was detected. Indian study by Dandona $\mathrm{L}$ et al, ${ }^{5}$ the most common indication for PK was corneal scarring accounting for 551 (28.1\%) cases, the most common cause was keratitis in $278(50.5 \%)$ followed by trauma $(21.0 \%)$ and undetermined in $25.6 \%$. Cases of corneal scarring with unspecified etiology are thought to be due to untreated keratitis. Thus two groups corneal scarring and active infectious keratitis together suggest that keratitis was responsible for great majority of cases forming single largest indication of PK in developing world similar to studies by Dandona $\mathrm{L}^{5}$ and Sony. ${ }^{5,14} \mathrm{M}$ Vanathi ${ }^{23}$ reported the most common primary etiology to be vascularized corneal scars $(66 \%)$, of which the scars related to infection were most common $(68.5 \%)$. In a study by Mohammad Hossien, ${ }^{24}$ the major indication of keratoplasty was corneal leucoma 75(62.5\%), which correlates with our study.

We found 10 cases of adherent leucoma. Price FW $\mathrm{Jr}$ et $\mathrm{al}^{25}$ and Dandona et $\mathrm{al}^{5}$ state that corneal scarring with vascularization or adherent leucoma and active infectious keratitis has a very poor prognosis for graft survival.

As compared to our study, PK's done for corneal scarring has been reported to be less in the developed world as in study by Mamalis $\mathrm{N},{ }^{8} \mathrm{R}$ J Morris, ${ }^{26}$ Liu E et al. ${ }^{27}$ Active infectious keratitis was an uncommon condition in reports from developed world which indicates difficulty faced by developing countries in treating infections indicative of problems prevalent in the developing countries related to availability, accessibility and affordability of eye care often leading to delayed diagnosis of corneal infections and consequent opacity.

We found $8(10.66 \%)$ cases of bullous keratopathy on histology of which pseudophakic bullous keratopathy (7/ 8) was the third most common indication for the PK and only one of aphakic bullous keratopathy similar to studies by Dandona et $\mathrm{al}^{5}$ while Dobbins et $\mathrm{al}^{28}(31.5 \%)$, S C Reddy et $\mathrm{al}^{29}(28.8 \%)$ reported it as their commonest indication. The most common cause of bullous keratopathy was intraocular surgery similar to study by Wang JY et al. ${ }^{13}$

We observed graft rejection in $4 \%$ recipients' where histology highlighted causes like stromal vascularisation, acute keratitis and bullous keratopathy (1 each / 3). It correlated with reports by Dobbins and Kanavi. ${ }^{28,30}$ The lower incidence of regrafts in our study could be due to good quality grafts or loss of follow-up. Indian studies by Aruna Kumari ${ }^{31}$ and Dandona et $\mathrm{al}^{5}$ have documented it as their second common indication. In our study we found that despite the significant visual improvement in most patients, factors like poor follow up, negligence to instill medications and poor hygiene lead to graft failure.

Fuchs' dystrophy was detected on histology in one case $(1.33 \%)$ in 49 years female who clinically presented with corneal opacity. Liu et $\mathrm{al}^{27}$ reported gender differences with female preponderance 3:1 ratio $(\mathrm{p}<0.001)$ in Fuch dystrophy. Many studies conducted in western countries reported Fuchs' dystrophy as an important indication with a rate of $9.3 \%$ as reported by study from UK. ${ }^{32}$ However, it was a rare condition in the present study $(1.33 \%)$ and other studies performed in Iran $(1.7 \%) .{ }^{24}$ Our study correlated well with reports by Kanavi et $\mathrm{al}^{30}$ and Dandona et al. ${ }^{5}$

We did not find any case of Keratoconus. The large series from the developed world by $\mathrm{R} \mathrm{J}$ Morris et $\mathrm{al}^{26}$ and Lindquist et $\mathrm{al}^{10}$ have reported that keratoconus makes $34.2 \%$ and $24.0 \%$ respectively being the most common indication for PK.

We found 1 case $(1.33 \%)$ of chronic actinic keratopathy (CAK)/ climatic droplet keratopathy $(\mathrm{CDK})$ in a 65 years old patient of corneal opacity who was farmer by occupation. Histology revealed eosinophilic material in corneal stroma which was negative for Congo red stain ruling out possibility of amyloid. [Fig. 3B]

Studies by Hugh Taylor and Gray $\mathrm{RH},{ }^{33,34}$ have reported $\mathrm{CDK}$ in elderly males with strong relation to occupation and that it is a degenerative condition leading to significant visual disability with UV light exposure to be the etiological factor.

Correlation of histopathology and clinical diagnosis is shown in Table 1.

Sensitivity, specificity, Positive Predictive value (PPV), Negative predictive value (NPV) of clinical diagnosis for infectious keratitis was $77.27 \%, 88.68 \%$, $73.91 \%$ and $90.38 \%$ respectively with $\mathrm{P}$ value $<0.001$. Sensitivity, specificity, PPV, NPV of clinical diagnosis for corneal ulcer was $86.49 \%, 76.22 \%, 78.05 \%, 85.29 \%$ respectively with $\mathrm{P}$ value $<0.001$. Concordance rate of clinical and histopathological diagnosis for infectious keratitis and corneal ulcer was $85.33 \%, 81.30 \%$ 
respectively as shown in table 2. Discordance was observed in infectious keratitis, corneal ulcer, Fuchs' dystrophy and also in chronic actinic keratopathy.

Rezaei Kanavi ${ }^{35}$ reported concordance rate of 97.5\%. Discordance was observed in acquired corneal endothelial decompensation, corneal dystrophies, infectious keratitis, and other causes, with the rate of $6.0 \%, 4.1 \%, 2.8 \%$, and $16.6 \%$, respectively. Sheldon $\mathrm{CA}$ et $\mathrm{al}^{36}$ reported discordance in $6 \%$ which occurred with clinical diagnoses of bullous keratopathy, Fuchs dystrophy or keratoconus.

Thus leading indication for PK in our series of patients was corneal ulcer/scarring followed by acute infectious keratitis which is similar to various studies done in developing countries indicating poor safety and inadequate medical services as compared to developed world. In developed countries most common indications were PBK, keratoconus and graft failure.
Of 81 donors cornea only one case showed changes of chronic actinic keratopathy whose age was 82 years. 6 corneas which were not transplanted within stipulated time showed changes of degeneration in the form of epithelial denudation and stromal degeneration with loss of keratocytes rest 74 showed normal histology [Table 3]

Vincent Borderie ${ }^{37}$ in their light microscopy study of 53 consecutive organ-cultured corneas reported stromal abnormalities like cellular edema, light and dark vacuoles, cell membrane disruption and, finally, internal cytolysis on TEM. Thus they emphasized the importance of light microscopy of corneal stroma during organ culture and advocated need to investigate if presence of degenerated keratocytes in the graft's stroma influences the outcome of transplantation.

Table 1: Showing clinicopathological correlation

\begin{tabular}{|c|c|}
\hline Clinical diagnosis $(n=75)$ & Histopathological diagnosis $(n=75)$ \\
\hline $\begin{array}{l}\text { Infectious keratitis }(n=23) \\
\text { including corneal abscess }\end{array}$ & $\begin{array}{c}\text { Acute keratitis-12(Bacterial) } \\
\text { Fungal keratitis-05 (Aspergillus-03, Fusarium- 02) } \\
\text { Healing ulcer-01, Healed ulcer- 02,Adherent leucoma- 02, } \\
\text { Non-commentable- 01 }\end{array}$ \\
\hline $\begin{array}{l}\text { Corneal ulcer / Opacities }(n=41) \\
\text { including adherent leucoma }\end{array}$ & $\begin{array}{c}\text { Adherent leucoma- 08, } \\
\text { Healing ulcer - 07, Healed scar-17, } \\
\text { Acute keratitis- 05, } \\
\text { Fuchs' dystrophy- 01, } \\
\text { Chronic actinic keratopathy- 01, } \\
\text { Non-commentable- } 02\end{array}$ \\
\hline Bullous keratopathy $(\mathrm{n}=8)$ & Bullous keratopathy- 08 \\
\hline Graft rejection $(n=3)$ & $\begin{array}{l}\text { Graft rejection due to - } \\
\text { stromal vascularisation (1), acute keratitis (1), } \\
\text { bullous keratopathy (1). }\end{array}$ \\
\hline
\end{tabular}

Table 2: Showing concordance rate between clinical and histopathological diagnosis

\begin{tabular}{|l|c|c|}
\hline \multicolumn{1}{|c|}{ Clinical diagnosis } & Histopathological diagnosis & Concordance rate \\
\hline $\begin{array}{l}\text { Infectious keratitis }(\mathrm{n}=23) \\
\text { including corneal abscess }\end{array}$ & 17 & $85.33 \%$ \\
\hline Corneal ulcer/ Opacities $(\mathrm{n}=41)$ & 32 & $81.30 \%$ \\
\hline Bullous keratopathy $(\mathrm{n}=8)$ & 08 & $100 \%$ \\
\hline Graft rejection $(\mathrm{n}=3)$ & 3 & $100 \%$ \\
\hline FD $(\mathrm{n}=0)$ & 1 & $0 \%$ \\
\hline CAK $(\mathrm{n}=0)$ & 1 & $0 \%$ \\
\hline NC $(\mathrm{n}=0)$ & 3 & $0 \%$ \\
\hline
\end{tabular}

FD- Fuchs' Dystrophy, CAK- Chronic actinic keratopathy, NC- Non commentable

Table 3: Histology of donors' corneal tissue

\begin{tabular}{|l|c|c|}
\hline \multicolumn{1}{|c|}{ Type of donors' tissue (n=81) } & \multicolumn{2}{|c|}{ Histology } \\
\hline Residual corneal tissue(From transplanted cornea) & \multirow{2}{*}{75} & UR- 74 \\
\cline { 2 - 3 } & & CAK-1 \\
\hline Corneal tissue(not transplanted) & $06-$ Degenerative changes \\
\hline Total & \multicolumn{2}{|c|}{81} \\
\hline
\end{tabular}

UR- unremarkable, CAK- Chronic actinic keratopathy 


\section{Conclusion}

The leading indication for PK in our series of recipients' was corneal ulcer/scarring followed by acute infectious keratitis which is similar to various studies done in developing countries. Bullous keratopathy and dystrophies were less as compared to developed countries. Keratitis and corneal scarring predominated due to large number of farm workers in our study with poor safety awareness and low medical services as compared to developed world. Thus, histopathology of cornea definitely gives additional insight to clinical diagnosis especially in categorizing corneal opacities. In addition, type of infectious organisms can be diagnosed on microscopy and culture.

\section{Reference}

1. Dandona R, Dandona L. Corneal blindness in a southern Indian population: need for health promotion strategies. Br J Ophthalmol. 2003;87(2):133-141.

2. Gupta N, Tandon R, Gupta SK, Sreenivas V, Vashist P. Burden of Corneal Blindness in India. Indian Journal of Community Medicine. 2013;38(4):198-206. doi:10.4103/0970-0218.120153.

3. Whitcher JP, Srinivasan M, Upadhyay MP. Corneal blindness: A global perspective. Bull World Health Organ. 2001;79:214-21.

4. Zirm EK. Eine erfolgreiche totale keratopastik (A sucessful total keratoplasty). Refract Corneal Surg. 1906;5:258-261.

5. Dandona L, Ragu K, Janarthanan M, Naduvilath T J, Shenoy R, Rao G N. Indications for penetrating keratoplasty in India. Indian J Ophthalmol. 1997;45:1638.

6. Price FW, Whitson WE, Collins KS, Marks RG. Fiveyear corneal graft survival: large, single- center patient cohort. Arch Ophthalmol. 1993;111:799-805.

7. Williams KA, Muehlberg SM, Wing SJ, Coster DJ. The Australian Corneal Graft Registry: 1990 to 1992 Report. Aust N Z J Ophthalmol. 1993;21(Suppl):1-48.

8. Mamalis N, Anderson CW, Kreisler KR, Lundergan MK, Olson RJ. Changing trends in the indications for penetrating keratoplasty. Arch Ophthalmol. 1992;110:1409-11.

9. Hyman L, Wittpenn J, Yang C. Indications and techniques of penetrating keratoplasty, 19851988. Cornea. 1992;11:573-76.

10. Lindquist TD, McGlothan JS, Rotkis WM, Chandler JW Indications for penetrating keratoplasty: 19801988. Cornea. 1991;10:210-16.

11. Brady SE, Rapuano CJ, Arentsen JJ, Cohen EJ, Laibson PR. Clinical indications for the procedures associated with penetrating keratoplasty, 1983-1988. Am J Ophthalmol. 1989;108:118-22.

12. Siganos CS, Tsiklis NS, Miltsakakis DG, Georgiadis NS, Georgiadou IN, Kymionis GD, et al. Changing indications for penetrating keratoplasty in Greece, 19822006: a multicenter study. Cornea. 2010;29:372-374.

13. Wang JY, Xie LX, Song XS. Trends in the indications for penetrating keratoplasty in Shandong, 2005-2010. Int J Ophthalmol. 2011;4(5):492-7.

14. Sony P, Sharma N, Sen S, Vajpayee RB. Indications of penetrating keratoplasty in northern India. Cornea. 2005;24:989-991.
15. Xie L, Song Z, Zhao J, Shi W, Wang F. Indications for penetrating keratoplasty in north China. Cornea. 2007;26:1070-1073.

16. Chen WL, Hu FR, Wang IJ. Changing indications for penetrating keratoplasty in Taiwan from 1987 to 1999. Cornea. 2001;20:141-144.

17. Parsons' Diseases of the Eye Section: IV, Chapter 15. In: Ramanjit Sihota, Radhika Tondon. Parsons' Diseases of the Eye, $21^{\text {st }}$ edition (Paperback). Elsevier Health Sciences;2011.

18. Myronn Yanoff. Cornea and Sclera. In: Russell Gabbedy.Ocular Pathology, $6^{\text {th }}$ edition. Elsevier;2009.

19. Gopinathan U, Garg P, Fernandes M. The epidemiological features and laboratory results of fungal keratitis: a 10-year review at a referral eye care center in South India. Cornea. 2002;21:555-559.

20. Sharif KW, Casey TA. Changing indications for penetrating keratoplasty, 1971-1990. Eye. 1993;7:485-8.

21. Rajpal Singh Punia, Reetu Kundu, Jagdish Chander, Sudesh Kumar Arya, Uma Handa, Harsh Mohan. Spectrum of fungal keratitis: clinicopathologic study of 44 cases. Int J Ophthalmol. 2014;7(1):114-117.

22. Sirikul T, Prabriputaloong T, Smathivat A, Chuck RS, Vongthongsri. A Predisposing factors and etiologic diagnosis of ulcerative keratitis. Cornea. 2008;27(3):2837.

23. M Vanathi, Namrata Sharma, Rajesh Sinha, Radhika Tandon, Jeewan S Titiyal, and Rasik B Vajpayee, et al Indications and outcome of repeat penetrating keratoplasty in India. BMC Ophthalmol. 2005;5:26.

24. Mohammad Hossien Davari and Hoda Gheytasi. Indications for Penetrating Keratoplasty and Epidemiological Study in Teaching Hospitals of Birjand Medical University from 1999 to 2006. www.intechopen.com

25. Price FW Jr, Whitson WE, Collins KS, Marks RG. Fiveyear corneal graft survival. A large, single-center patient cohort. Arch Ophthalmology. 1993 Jun;111(6):799-05.

26. R J Morris, A K Bates. Changing indications for keratoplasty. Eye. 1989;3:455-59.

27. Liu E, Slomovic AR. Indications for penetrating keratoplasty in Canada, 1986-1995. Cornea. 1997 Jul;16(4):414-9.

28. Dobbins KR, Price FW Jr, Whitson WE. Trends in the indications for penetrating keratoplasty in the midwestern United States. Cornea. 2000 Nov;19(6):813-6.

29. Reddy SC,Tajunisah I. Indications for penetrating keratoplasty in west Malaysia. Int J Ophthalmol. 2008;1(2):125-128.

30. Kanavi MR, Javadi MA, Sanagoo M. Indications for penetrating keratoplasty in Iran. Cornea. 2007;26(5):5613.

31. Aruna Kumari, Roopam Gupta. Indications for Penetrating Keratoplasty in Western India. International Journal of Recent Trends in Science And Technology. 2013;8:256.

32. N Al-Yousuf, I Mavrikakis, E Mavrikakis, S M Daya. Penetrating keratoplasty: indications over a 10 year period. Br J Ophthalmol. 2004;88:998-1001.

33. Hugh R. Taylor. Aetiology of climatic droplet keratopathy and pterygium. British Journal of Ophthalmology. 1980;64:154-63.

34. Gray RH, Johnson GJ, Freedman A. Climatic droplet keratopathy. Surv Ophthalmol. 1992;36(4):241-53.

35. Rezaei Kanavi M, Javadi A, Javadi MA, Yaseri M, Feizi S. Concordance between clinical and histopathologic diagnosis in recipient corneas. Eur J Ophthalmol. 2011;21(6):691-4. 
36. Sheldon CA, McCarthy JM, White VA. Correlation of clinical and pathologic diagnoses of corneal disease in penetrating keratoplasties in Vancouver: a 10-year review. Can J Ophthalmol. 2012;47(1):5-10.

37. Borderie V, Martinache C, Sabolic V, Touzeau O,

Laroche L. Light microscopic evaluation of human donor corneal stroma during organ culture. Acta Ophthalmol Scand. 1998;76(2):154-7. 